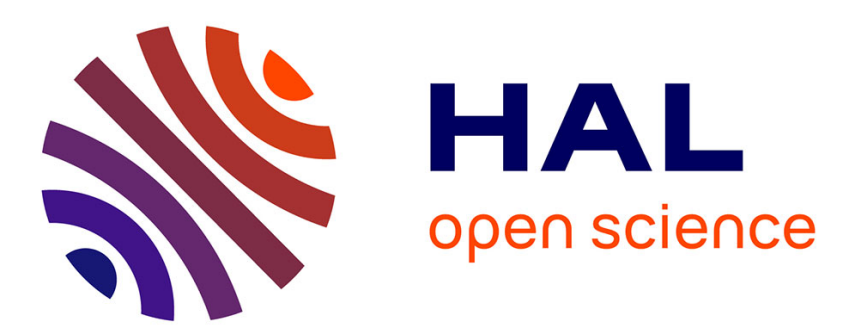

\title{
Une divinité de circonstance. Le culte de Hoàng Công Chất à Điện-Biên-Phủ
}

\author{
Philippe Le Failler
}

\section{To cite this version:}

Philippe Le Failler. Une divinité de circonstance. Le culte de Hoàng Công Chất à Điện-Biên-Phủ. Bulletin de l'Ecole française d'Extrême-Orient, 2006, 93 (1), pp.183-205. 10.3406/befeo.2006.6035 . halshs-02558417

\section{HAL Id: halshs-02558417 https://shs.hal.science/halshs-02558417}

Submitted on 29 Apr 2020

HAL is a multi-disciplinary open access archive for the deposit and dissemination of scientific research documents, whether they are published or not. The documents may come from teaching and research institutions in France or abroad, or from public or private research centers.
L'archive ouverte pluridisciplinaire HAL, est destinée au dépôt et à la diffusion de documents scientifiques de niveau recherche, publiés ou non, émanant des établissements d'enseignement et de recherche français ou étrangers, des laboratoires publics ou privés. 


\section{Une divinité de circonstance. Le culte de Hoàng Công Chất à Điện-} Biên-Phủ

Philippe Le Failler

\section{Citer ce document / Cite this document :}

Le Failler Philippe. Une divinité de circonstance. Le culte de Hoàng Công Chất à Điện-Biên-Phủ. In: Bulletin de I'Ecole française d'Extrême-Orient. Tome 93, 2006. pp. 183-205;

doi : https://doi.org/10.3406/befeo.2006.6035

https://www.persee.fr/doc/befeo_0336-1519_2006_num_93_1_6035

Fichier pdf généré le 08/02/2019 


\title{
Résumé
}

Philippe Le Failler

Une divinité de circonstance. Le culte de Hoàng Công Chất à Điện-Biên-Phủ

$\mathrm{Au}$ XIIle siècle, un vaste mouvement de révoltes paysannes secoua le nord du Vietnam. Afin d'échapper aux troupes des seigneurs Trịnh, Hoàng Công Chất, l'un des meneurs, se réfugia à Mường Thanh (Điện-Biên-Phủ), aux confins du royaume, s'y fortifia et entrepris d'y établir son pouvoir quinze ans durant. Chaque année, au mois de février, dans un temple reconstruit, un culte lui est dédié localement. Les différences notables entre le récit d'époque et le mythe recréé par les autorités mettent en évidence des enjeux très contemporains. Désormais, dans les zones frontalières du Vietnam, l'État se livre à une réinterprétation des événements historiques afin de favoriser la propagation de l'idée nationale et l'émergence d'une cohésion interethnique. Ce faisant, il s'inscrit dans une pratique plus ancienne où la promotion du culte des grands personnages historiques s'exerce jusque dans les villages et contribue ainsi à la diffusion d'une conception centralisée de l'ordre social.

\begin{abstract}
Philippe Le Failler

Une divinité de circonstance. Le culte de Hoàng Công Chất à Điện-Biên-Phủ

In the XVIIIth century, a large movement of peasant uprisings shook the North of Vietnam. In order to escape troops of the Trịnh Lords, one of the local leaders, Hoàng Công Chất, took refuge in Điện-BiênPhủ, then a remote border area of the kingdom, where he began to establish his authority for over fifteen years. Each year, in February, a worship is dedicated to him in a rebuilt temple. Substantial differences between the chronology of events and the myth recreated by the authorities point up to some of the contemporary issues at stake. Henceforth, in the far-off mountainous regions of Vietnam, the State participates in a reinterpretation of historical events to promote the idea of the nation and to strengthen cohesion among ethnic groups. In doing so, this state-sponsored activity refers to an ancient practice where, even within villages, worship of major historical figures is promoted, thus contributing to the promotion of an image of social order proceeding from the central government.
\end{abstract}




\title{
Une divinité de circonstance Le culte de Hoàng Công Chất à Điện-Biên-Phủ
}

\author{
Philippe Le Failler
}

Situé au cadran nord-ouest du Vietnam, le vaste bassin de la Sông Đà (dite rivière Noire) faisait jadis partie des marches de l'empire. Pour l'administration de la capitale, cet espace montagneux constituait la province de Hưng-Hóa mais il était aussi désigné par l'expression Sip-song-châu-thai (soit les douze seigneuries tai). À l'inverse du delta du fleuve Rouge, hérissé de pagodes, de temples et de maisons communales, où l'empreinte du passé et des hommes illustres reste partout présente, peu de figures religieuses ou historiques y sont honorées. Sans doute faut-il imputer cette absence au sentiment religieux diffus que manifestent les Tai, ici la composante majoritaire de la population: contrairement au Laos voisin où l'influence du bouddhisme est forte, cette région ne recèle pas ou peu de temples. De même, les sites naturels ou construits qui témoignent de l'histoire ancienne sont rares et, pour les plus anciens, l'on ne distingue que deux stèles qui furent érigées en 1433 sur ordre du souverain Lê-Lợi '. Elles se situent au bord de la rivière Noire, l'une à Lai-Châu l'autre à Hoà-Bình, soit à deux extrémités du bassin dans sa partie vietnamienne. Ces témoignages attestent que le pouvoir central devait, de temps à autre, réaffirmer son primat sur des territoires peuplés de groupes ethniques alors tributaires. L'histoire régionale proprement dite, orale ou compilée dans les chroniques locales des Tai, si elle nous est connue dans ses grandes lignes, l'est cependant avec moins de détails que celle des plaines. Les événements qui ont marqué les populations et les lieux de mémoire ne donnaient pas matière à l'édification de temples commémoratifs mais ont fourni plutôt les thèmes des épopées chantées.

Des vestiges plus récents datant de la période coloniale ou de la guerre d'Indochine sont désormais reconnus comme sites historiques. Premier d'entre eux,

1. Cf. Émile Gaspardonne, «Annamites et Thai au xve siècle », Journal Asiatique. 1939. p. 405-436. 
à la symbolique avérée, le théâtre de la bataille de Điện-Biên-Phủ de 1954 : ses collines, ses tranchées, ses carcasses de chars, ses canons épars mais plus encore ses mémoriaux et monuments aux morts, vietnamiens ou français, ses statues gigantesques érigées pour les commémorations du cinquantenaire, son musée etc. En ce lieu particulier, chargé d'histoire récente mais aussi terre d'élection de nombreux migrants venus du delta du fleuve Rouge depuis 1954, s'est constitué un mélange de population où les Việt nouvellement arrivés (ou Kinh, soit $85 \%$ de la population du pays) s'agrègent aux Tai de peuplement plus ancien. Les villages des uns et des autres se mêlent peu et sont aisés à distinguer par l'architecture des bâtisses : maisons de bois sur pilotis pour les Tai, en brique et de plain-pied pour les Việt.

Toutefois, un personnage relevant de l'histoire ancienne est célébré à Điện-BiênPhủ. Il s'agit de Hoàng Công Chất, un révolté de l'ethnie việt fuyant les troupes impériales qui s'est établi à Mường-Thanh (non du lieu en thaï) au XviI' siècle. S'il faut en croire la légende, il serait parvenu en ces lieux à la tête d'une petite troupe et aurait rassemblé la population locale tai pour repousser une invasion venue du Laos. Ce haut fait lui vaut d'être honoré une fois l'an dans un temple qui lui est dédié situé à l'emplacement d'une ancienne citadelle, au sud de la ville de Điện-Biên, soit au centre de la plaine.

Ce culte unique suscite la curiosité : pourquoi un Việt est-il honoré en terre tai à la manière des gens du delta? Quelle valeur symbolique et politique la présence de son temple signale-t-elle et sur quelle tradition s'appuie-t-on? Plusieurs points méritent d'être soulignés sur la réalité historique du personnage, la transformation progressive de sa représentation, l'environnement humain de son lieu de culte, l'opportunité de réactiver ce dernier et sa très contemporaine mise en scène. Comme, de toute évidence, les modalités de culte sont calquées sur une liturgie việt, la comparaison s'impose avec les pratiques en vigueur quelque $300 \mathrm{~km}$ plus à l'Est.

\section{De la divinisation des personnages historiques}

Dans le delta du fleuve Rouge, les populations việt pratiquent de longue date le culte des divinités tutélaires (thành hoàng). Ce sont souvent des personnages remarquables de l'histoire nationale dont la représentation figurée dans les maisons communales (dinh) s'amalgame au culte des ancêtres fondateurs du village. Tel héros, général ou grand mandarin d'antan, se trouve logiquement honoré dans son village d'origine, sur les lieux de ses faits d'arme mais également dans des villages sans lien direct avec l'œuvre réalisée. La création d'un panthéon de héros divinisés se faisait jadis avec l'assentiment obligé de l'administration impériale qui délivrait des brevets de divinités. Le choix des personnages dignes d'être révérés localement était donc un privilège du pouvoir central. En officialisant le culte des thành hoùng, l'État s'offrait un moyen commode de diffuser son idéologie et, par ce biais, gardait néanmoins un contrôle constant des cultes en évitant l'émergence de divinités indésirables. De nos jours encore, les cultes et religions sont étroitement encadrés par l'État vietnamien qui reste très pointilleux sur la question et reproduit, peu ou prou, une politique plus ancienne.

La visite d'une maison communale, d'une pagode ou d'un temple en 2006 ne manque pas de faire ressortir la présence de plus en plus fréquente du portrait de Hồ Chí Minh à la place d'honneur. Emblématique du communisme vietnamien, et plus 
encore symbole du combat national, le personnage est omniprésent. Figure obligée, déjà représentée sur tous les billets de banque, dans les bureaux d'État et référence nécessaire des discours officiels, il renforce sa présence dans la sphère privée. I es horloges, les calendriers et autres objets de la vie quotidienne à son effigie pénètrent les foyers. L'hommage qui lui est rendu, passant de la révérence à la vénération, procède de la perpétuation du phénomène de divinisation des héros nationaux. Dans ce cas précis, nul besoin de demander l'assentiment des autorités tant le personnage est consensuel.

Le cas du défunt président, dont le portrait glisse de la tribune à l'autel, peut sembler atypique. On constate néanmoins, pour des personnages plus anciens, un renforcement des pratiques cultuelles qui s'effectue sous les auspices de l'État. Que celui-ci continue à se définir comme communiste et prône l'athéisme ne semble pas, en l'occurrence, contradictoire avec l'idée religieuse si celle-ci va de pair avec la promotion de l'idée nationale. Les rois Hùng ayant régné sur le pays des Việt dans des temps reculés, souverains mythiques s'il en est puisque issus des amours d'une déesse et d'un dragon, font l'objet de cérémonies où participent les plus hauts personnages du Parti et de l'État. Le principe est de mêler cérémonie et festival, de fondre le mythe dans le folklore jusqu'à cristalliser la doctrine nationale ${ }^{2}$. À voir les dignitaires de l'un des derniers régimes marxistes de la planète se ployer devant l'autel et déposer pieusement leurs bâtonnets d'encens au mois d'avril, on songe au chemin parcouru depuis la destruction des pagodes telle qu'elle se pratiquait dans les années 1960 .

Les revirements idéologiques de cette période de « renouveau ", toute dédiée au pragmatisme, font fi du grand écart entre la doctrine, qui varie peu, et la pratique qui se situe à cent lieux. Puisque la liberté religieuse est revendiquée, il importe d'encadrer les pratiques, d'orienter le sujet du culte et de donner sens à des croyances anciennes. La réalité historique est vite délaissée au profit d'une idéologie nationaliste dans ce qui paraît, selon toute vraisemblance, un choix politique. Les symboles susceptibles de servir le patriotisme, aussi ténus soient-ils, sont accaparés par l'idéologie officielle qui les insère dans son appareil de propagande. Cela nécessite une simplification extrême des symboles représentés et la désincarnation est menée jusqu'à l'épure. La divinité tutélaire devient donc, par définition et au terme du processus de glorification puis de divinisation, le contraire d'un personnage historique. Autant ce dernier peut être étudié et envisagé sous les aspects contradictoires de sa personnalité et de son action, autant son immortalisation réduit l'homme à une icône et résume l'œuvre à ses vertus morales.

Entre le toujours contemporain Hồ Chí Minh et les rois Hùng des mythes fondateurs, tous d'envergure nationale, quelle est la place laissée aux divinités tutélaires issues de figures locales? À quelle valeur d'exemplarité se rattache-t-on ? Le cas du culte de Hoàng Công Chất, dont la vie tumultueuse est loin d'indiquer un personnage à l'éthique sans tache, donne un exemple frappant de la sélection opérée dans ses chapitres biographiques. Il illustre la pénétration des pratiques cultuelles

2. "La fète (...) exacerbe le patriotisme. la fierté nationale, manifeste la reconnaissance vis-à-vis des rois Hïng, fondateurs du pars, consolide le bloc d'union nationale et contribue à valoriser la culture vietnamienne " Article de Thu Trang préludant aux festivités des 14-18 avril à Việt-Trì intitulé « Tout est prêt pour le jour $\mathrm{J}$ ». Hanoi, Courrier du Vietnam. 11 avril 2005. 
việt dans un lieu où ces immigrés de fraîche date, pièces rapportées certes mais relevant de la culture nationale dominante, parviennent avec succès à introduire une légitimité sur une terre qu'ils cultivent au quotidien avec le culte de l'aventurier du XVIII siècle.

Il apparaît que l'on ne trouve aucune mention d'un temple ou d'un culte dédié à ce personnage dans les chapitres des géographies impériales établies par les mandarins de la dynastie des Nguyễn au xIx ${ }^{\mathrm{e}}$ siècle $^{3}$. Seul Phạm Thận Duật fait allusion à un temple sis à Điện-Biên et dédié à Hoàng Công Chất dans son Hung Hóa ký luợc pour la période où il était mandarin dans la région (1853-1856) ${ }^{4}$. Pendant la période coloniale, faisant office d'administrateurs, les officiers français installés à demeure, eux aussi prolixes en rapports et relations savantes, n'en disent rien. Les uns et les autres mentionnent pourtant avec précision les points d'intérêt d'une contrée peu peuplée où les distractions sont rares et les sites remarquables comptés. Il semble donc que le culte livré à Hoàng Công Chất n'était pas officialisé par la Cour car aucune mention de brevet royal de divinisation ne vient l'entériner ${ }^{5}$. De plus, il ne relève pas d'un exercice continu qui prendrait son origine à l'époque des faits. Au mieux peut-on envisager qu'il a connu d'assez longues éclipses et plus probablement qu'il résulte d'une recréation il y a une vingtaine d'années. Ce culte, encouragé par les autorités, a récemment connu un renouveau dont témoigne à la fois la construction d'un véritable temple et la pratique de rites qui n'apparaissent en rien liés à l'environnement tai mais sont manifestement inspirés du culte à la divinité tutélaire des villages việt tel que pratiqué dans le delta.

\section{La fête annuelle}

Les festivités entourant la cérémonie annuelle du décès de Hoàng Công Chât débutent le $25^{\circ}$ jour du $2^{\mathrm{C}}$ mois lunaire. Elles font l'objet d'annonces préalables par voie de presse ainsi que par la télévision locale. Pour l'année 2005, la fête durant deux jours, l'inauguration est prévue à 7 h 30 le 2 avril, soit la veille de la date annivcrsairc du décès de la divinité. Les autorités de la province sont dûment représentées au plus haut niveau. Ce samedi, à Bản-Phủ, à dix kilomètres au sud du chef-lieu de province, le temps est clément et il fera même chaud sur le coup de midi.

3. Parmi les grandes géographies impériales du XIXe siècle, signalons que le Đại Nam nhát thống chi (1882) n'indique qu'une pagode utilisée par des Lào au xã de Ba-Man, et que le Đồng Khánh địa dur chi (1886-1888) mentionne lui aussi au xã de Nông-Hiệ une pagode Lào. Aucune des deux ne fait mention de Hoàng Công Chất. Sans doute est-ce la pagode Cố-Thành mentionnée parmi les temples remarquables de la province. Cf: Dại Nam nhất thông chi, trad. Vict. du Viện Sứ Học, Rééd NXB Thuận-Hóa 1997. 5 vol., tome 4, p. 328. Dồng Khánh dịa dur chi lurọ̣c. Ed. et trad. par Ngô Đức Thọ, Nguyễn Văn Nguyên et Ph. Papin en 3 vol., EFEO Hanoi, 2003, p. 739.

4. Phạm Thận Duật indique dans le Hurng Hóa ký lượ (1856), au chapitre consacré aux temples et pagodes que dans la citadelle du phi de Điện-Biên (ancienne citadelle de Trình-Lệ) se trouve un temple consacré au rebelle Chất. Phạm Thận Duật Hưng Hóa Ki Lurợ', in Phạm Thận Duật cuộc đời và tác phầm Hà Nội, 2000, NXB Văn hoá Thông tin. 838 p. ici p. 157 en trad. vietnamienne et p. 645 en texte original.

5. Toute recherche dans la Bihliographie des légendes des génies anx villages vietnamiens et des brevets rolatax de divinisation (Viện Thông tin Khoa Học Xã Hội thur muc thàn tich thà̀n sắc, Hanoi, 1996) reste vaine. Ceci n`a rien de surprenant concernant la haute Région et particulièrement la province de Hurng-Hóa où la faible implantation des Việt ne justifiait pas l'édification de temples et de pagodes : mais cette absence consacre aussi l'idée que le personnage n'était pas révéré dans son village d'origine du delta. 
La première impression est d'entrer dans une forteresse, murailles peintes de rouge et porche de citadelle surmonté d'une pancarte ou s'étale, en caractères gothiques, la

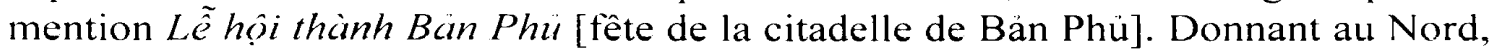
les remparts larges de cinq mètres et hauts d'autant, flanquent la porte sur environ cinquante mètres de chaque coté mais forment un mur unique qui atteste, si besoin était, sa création récente et le fait qu'il ne s'agit point d'une enceinte de protection ancienne. Une allée de deux cents mètres mène vers une vaste maison thaïe bâtie sur pilotis qui n'est autre qu'une annexe de la maison de la culture. De part et d'autre de la voie bétonnée, pour un effet esthétique plus que poliorcétique, se trouvent deux bassins intérieurs figurant des douves une fois la porte franchie.

C'est sur la gauche, à égale distance entre la porte et la maison tai, que se trouve le temple de Hoàng Công Chất. La disposition des lieux en L, le soin apporté aux constructions et surtout la présence de deux banians de grande taille donnent à l'ensemble un aspect assez harmonieux. Deux bâtiments et un autel extérieur composent l'ensemble cultuel situé sur une plate-forme surélevée d'environ un mètre cinquante à laquelle on accède par un escalier. L'autel couvert, sous la frondaison du plus grand arbre, s'élève sur la droite. On y accède par une volée d'une dizaine de marches. Il abrite une stèle sombre et de gravure récente retraçant en écriture romanisée (quốc ngũu) et à grands traits la vie de Hoàng Công Chất et sa contribution à l'histoire locale. On y célèbre les mérites acquis par « sept seigneurs du peuple Kinh". Là brûlent des bâtonnets d'encens. Prennent place pour une haie d'honneur une dizaine de jeunes gens vêtus, qui de vert, qui de brun, d'un uniforme militaire d'antan. Ils portent à la taille une ceinture bó que couleur or, sont coiffés de chapeaux de soldats nón dấu et arborent des épées en bois. À quelques mètres, de l'autre côté du banian, un second autel, en plein air et sans mention aucune, semble dédié plus particulièrement à l'arbre et aux divinités qui l'habitent.

Bordant la cour au Nord, le premier bâtiment sur la gauche, de taille modeste, est en fait l'ancien temple qui s'ouvrait au Sud face aux deux arbres. Ce lieu de culte est d'une ancienneté toute relative d'ailleurs puisque, selon toute vraisemblance, l'édifice désormais désaffecté et remplacé par une construction plus grande ne date que d'une douzaine d'années.

Le bâtiment central, temple actuel, est construit à la manière des đinh à trois travées. De son architecture émane une certaine élégance. Les détails sont soignés avec des angles de toits incurvés et ornés de dragons, une couverture de tuiles, des claustras et une charpente de bois brut. Le temple s'ouvre à l'Ouest par des vantaux de bois ajourés sur pivot et donne sur la place. À l'intérieur, trois autels successifs reçoivent les offrandes: fruits, encens mais aussi des bouteilles de vin. Seul le dernier autel est inaccessible au public où trônent les sept statuettes qui représentent Hoàng Công Chất et ses fidèles en tenue de mandarin. Les colonnes sont ornées de formules en caractères qui, figurant des sentences parallèles, livrent un résumé de la vie de la divinité. À droite de l'autel, elle aussi en écriture romanisée, la stèle " ancienne " côtoie une cloche de fonte récente. Il apparaît très vite, hormis peutêtre les statues laquées sur l'autel, que le reste du décorum est de facture nouvelle, datant de 2004 tout au plus. 
Mais revenons aux festivités lors desquelles la cérémonie cultuelle ne doit débuter qu'après l'inauguration officielle par les représentants de l'autorité assis pour l'heure sous le grand banian. Dans un premier temps l'orgue électrique fait patienter l'assistance qui grossit où se remarquent surtout la coiffure des femmes tai et les casquettes vertes des forces policières. Puis trois discours très brefs se succèdent qui procèdent à un rappel succinct des mérites de Hoàng Công Chất, reprennent les éléments inscrits sur la stèle et les recadrent dans la politique d'union nationale en mentionnant la bataille de Điện-Biên-Phủ et le rôle dirigeant du Parti communiste. La foule de trois cents personnes écoute poliment les allocutions et voit, une fois celles-ci terminées, les représentants de l'autorité gravir les marches de l'autel et déposer leurs bâtonnets d'encens. La commémoration étant achevée, la célébration proprement dite peut maintenant débuter de l'autre côté de la place, les outils de sonorisation sont rangés et deux tambours prennent la relève.

Face au temple, un palanquin couvert rouge et or est posé au centre de la cour dos au temple. Surmonté de deux parasols, il ne contient que des bougies et des plateaux d'offrandes. Le flanquant à trois mètres, deux râteliers d'armes rituelles, ou lồ bọ, sont servis chacun par trois femmes vêtues de noir et portant une coiffure ornée des mêmes motifs décoratifs que celui des femmes tai. Contrairement aux pratiques du delta, si les éléments d'une procession traditionnelle việt sont réunis,cette dernière n'aura pas lieu. La cérémonie, qui dure une vingtaine de minutes est exclusivement féminine si l'on fait abstraction des trois musiciens. La maîtresse de cérémonie (đại tế) est vêtue d'une tunique áo dài rouge et d'un pantalon blanc, d'une cape jaune et est coiffée d'une tiare rouge et or. Elle est secondée par deux femmes âgées qui servent de maîtres adjoints (bồi tế), immobiles des deux cotés du palanquin, au Nord et au Sud. Au son du tambour, la douzaine d'assistantes, toutes d'un âge certain et vêtues d'áo dài aux couleurs vives ou pastels, avancent à pas rythmé pour procéder aux trois offrandes successives et aux quatre prosternations.

Un non-spécialiste peut cependant noter que cette cérémonie est indiscutablement việt, aucun élément local tai ne vient la parasiter. Toutefois elle détonne par son exclusif féminin, l'abscncc de procession, lc manque de drapeaux rituels, mais aussi par son assistance composite, où ne sont présents ni les dignitaires ni les anciens. À n'en pas douter, il s'agit ici d'une création, un peu simplifiée, inspirée des anciennes cérémonies du delta. Quant aux jeunes « soldats », ils ne participent pas, comme il serait de règle, mais forment une haie auprès de l’autel extérieur pendant l'inauguration officielle.

Vers $9 \mathrm{~h}$, une fois la cérémonie achevée, la fête populaire débute où sont surtout présents des Tai. Les femmes mariées en grand costume et portant haut leur chignon dardé d'une piastre d'argent forment la ronde et dansent le $x o \dot{e}$ au son d'un grand tambour. Les jeunes fillles, à quelques exceptions près, sont, quant à elles, vêtues d'un jean et portent les cheveux longs. L'atmosphère est conviviale et annonce la kermesse à venir. Dans la meilleure humeur les villages s'affronteront au tir à la corde, hommes et femmes confondus. Les festivités qui se résument à un stand de tir et à quelques cotillons se poursuivront le lendemain, jour de pluie. Les émigrés vietnamiens se succèderont, assez nombreux, pour présenter leurs offrandes dans le temple ou sur l'autel extéricur avec une ferveur non feinte.

Quelques éléments sont à souligner. D'une part, si la présence des autorités et leur discours solennel laisse entendre qu'un culte autorisé est par définition un culte 
utile, la présence d'une assistance non négligeable guidée, les uns par la piété, les autres par l'occasion de se retrouver entre hameaux et le reste par la curiosité, tout témoigne d'un caractère bon enfant. Le premier jour les Tai forment la majorité des participants, qui sont par contre totalement absents le lendemain, remplacés par des Việt. Quant aux Hmong, aucun d'entre eux ne viendra, la saison est celle des travaux des champs durant laquelle ils descendent peu de leurs hauteurs. Pourtant souhaité, le mélange des ethnies s'opère peu. D'autre part, le soin de la mise en scène et du faire savoir, les investissements importants que représentent la construction des bâtiments et la surface occupée par le complexe, tout indique qu'il s'agit, au delà d'un temple, d'un site culturel créé à dessein. Il permet aux migrants venus du delta et dépourvus de pagodes de procéder au culte des ancêtres; et, à défaut d'un fondateur du village clairement identifié, Hoàng Công Chất, originaire de TháiBình comme beaucoup de nouveaux venus, fait parfaitement l'affaire. Aussi n'est-il pas surprenant, en interrogeant la population sur l'identité de la divinité, de voir ressurgir les mêmes thèmes : c'est un Việt, un paysan insurgé contre l'ordre féodal, un protecteur des frontières nationales et, en dernier lieu, le porte-parole de l'union des ethnies nationales. La population environnante connaît en réalité très mal la divinité et n'a guère d'opinion sur la version servie par les autorités.

\section{Pour une biographie reconstituée du personnage historique}

Le personnage de Hoàng Công Chất est assez méconnu, hormis quelques traits qui laissent l'imagination et la propagande libres de meubler les vides. Aucun ouvrage récent ne lui est consacré en propre et seul Đặng Nghiêm Vạn semble s'y être intéressé avec une certaine constance. Les quelques articles sur ce sujet, déjà anciens puisque datés des années 1960, prennent leurs informations à la source des annales impériales. Or ces dernières, en compilant au XIX ${ }^{\circ}$ siècle une documentation plus ancienne, la résument et l'interprètent. Le retour aux sources premières, ainsi qu'une comparaison avec les chroniques tai, permet d'étoffer nos connaissances et de livrer un résumé plus précis de la vie de l'homme vénéré à Điện-Biên.

Chất apparaît dans les annales historiques comme l'un des nombreux révoltés de l'année 1739. Les insurrections abondaient dans la partie nord du Vietnam en cette moitié de XVIII" siècle marquée par une crise dynastique et par une série de calamités naturelles. On n'en compte pas moins de vingt-huit qui, pour la majeure partie d'entre elles, débutèrent entre 1737 et 1744. La majorité de ces révoltes, plus précisément dix-neuf sur vingt-huit, furent matées en un ou deux ans. Cinq d'entre elles s'étalèrent sur plus de dix ans, seules celles de Hoàng Công Chất et du prince Lê Duy Mật perdurèrent jusqu'en 1770. S'ils échappèrent à la Cour et aux troupes lancées à leur poursuite pendant trente ans, cette bonne fortune est due à une fuite vers l'inconnu des confins montagneux. Cette particularité leur permit d'éviter l'issue funeste qui sera celle des autres bandes insurgées. Trop ancrés autour de leur village d'origine, ces paysans rebelles ne furent pas en mesure de résister longtemps aux troupes de la capitale. Plus audacieux peut-être, Hoàng Công Chất avait fait le pari de la montagne où, accompagné d'une dizaine de compagnons, il parvint à s'établir à Mường Thanh, soit à Điện-Biên-Phú, une quinzaine d'années durant 
(le nom local de Mường Thanh est parfois vietnamisé en động de Mãnh-Thiên ou Thanh-Châu). Là se situe l'épisode qui justifie le culte qui lui est rendu.

Pour le pouvoir vietnamien, Hoàng Công Chất n'était encore qu'un rebelle à son autorité qui, s'étant rendu maître du bassin de la rivière Noire, menait des coups de main aux abords du delta et s'alliait avec Lê Duy Mật, le prince rebelle alors retranché dans la province du Trấn-Ninh (de nos jours Xieng-Khouang au Laos mais qui, à l'époque, versait un tribut à la Cour). Sur l'instigation du seigneur Trịnh Sâm qui venait de succéder à son père Doanh, et après bien des vicissitudes, les troupes impériales finirent par monter une opération victorieuse en direction de Mường Thanh. À leur arrivée, les impériaux ne trouveront qu'une citadelle vide, qu'ils araseront, et la dépouille de Chất, décédé entretemps.

Les détails de l'expédition militaire nous sont connus par le récit de la pacification du Hưng-Hóa ${ }^{6}$ qui fut établi suite au retour victorieux des troupes dans la capitale. Cette relation officielle de la campagne militaire contre Hoàng Công Chất est ici le texte de référence, presque par défaut. Il retranscrit néanmoins une vision de la capitale, normée et partielle, car elle occulte entre autres les liens entre les insurgés et les populations locales. Tout à la gloire du seigneur qui décide de la campagne militaire, le texte fait évidemment peu de cas de la personnalité du rebelle, ni même de ses motifs. À vrai dire, le portrait qu'en dressent les rédacteurs est peu flatteur. De Hoàng Công Chất nous ne connaissons que l'évocation d'un rebelle aussi opiniâtre qu'aventureux. Cependant, procédant par résumés, le texte se contredit en bien des points et peine à retracer une chronologie approximative. Par ironie du sort, la campagne de pacification du Hưng-Hóa ne commence véritablement qu'une fois Hoàng Công Chât mort. Aussi revenons sur son parcours tel que nous pouvons le reconstituer sur presque 30 ans.

\section{La pacification du Hung-Hóa}

Né en 1706 dans le district de Thư-Trì, province de Thái-Bình ${ }^{7}$, Hoàng Công Chất, de son vrai nom Hoàng Công Thư, se révolta en 1739. Il n'était alors qu'un des nombreux « rebelles de Ngân-Già » (la région où ils sévissaient). Toutes les troupes lancées contre lui en 1740 ne rencontrèrent que l'échec. Puis il fit cause commune

6. Le Binh Hung thục luc (BH). Récit officiel de la pacification par les seigneurs Trịnh du soulèvement de Hoàng Công Chât au Hưng-Hóa. 1767-1769. 38 p. en Hán, Paris, Socićté Asiatique, fonds Henri Maspero HM 2211; Hanoi, Institut Hán-Nôm, VHv 2339, manus., 28,5 x 16,6, 38 p. Ce texte a fourni pas moins de cing pages aux annales du Curong muc. L'ensemble des informations relatives aux affaires du Hưng-Hóa pour la période concernée y sont contenues. Douze notices mensuelles sont consacrées, en tout ou partie, à Hoàng Công Chất. Parmi celles-ci, cincl sont des résumés ou de simples copies du texte original. Elles portent sur les années $1767,6^{\circ}$ et $10^{\circ}$ mois, le premier mois de 1768 et les deux premiers mois de 1769, done situées pour l'époque des faits. Toutefois. il convient d'y rajouter les notices mensuelles pour les faits antérieurs. Nous avons cclles de 1739 (12* mois), 1740 $(1,3)$, $1743(5,3), 1744(3), 1745(12), 1748(9), 1751$ (12), 1761 (5). Il semble que, selon les périodes, les documents à la disposition des historiens des annales impériales du XIX $x^{\circ}$ siècle aient varié en volume et en qualité. Sur la campagne du llưng-Hóa, le Binh Honng thẹc luc paraìt bien avoir été la seule source utiliséce.

7. Plus précisément du thòn de Hoàng-Xá, commune de Nguyên-Xá, district de Vũ-Thư au Sơn-Nam Hạ (Thái-Bình). Le Curong muc (XXXIX. 31) souligne que des sources le donnent natif du village de Vân-Hoàng. hự̣̂̂n Phú-Xuyên. 
avec Nguyễn Hữu Cầu, autre insurgé célèbre (CM XXXVIII, 29) et ensemble ils semèrent le trouble sur tout le sud-est du delta du fleuve Rouge, c'est-à-dire les riches terres rizicoles. Le prestige de Hoàng Công Chất s'adossait à une réputation de force et de violence. Il bénéficia un temps de l'inefficacité gouvernementale due aux querelles personnelles qui opposaient Nguyễn Công Thái alors gouverneur (trấn-thú) du Thanh-Hoa à Đỗ Thế Giai et Đàm Xuân Vực en cour auprès du Seigneur Sâm. Dénoncé comme incapable de capturer Chất, le gouverneur fut destitué en 1743 (CM XXXIX, 31). C'est à cette époque que l'expression " giăc co ", (bandit en herbe ou bandit des herbages, maquisard) semble avoir été utilisée, illustrant la capacité des insurgés à se fondre dans le paysage sans laisser de traces et comme dotés d'ubiquité ${ }^{8}$. De toute évidence plus mobiles, rompues à la guerre de harcèlement, les bandes rebelles restaient hors de portée des armées lancées à leur poursuite.

Chất est à ses débuts présenté comme une canaille de peu d'envergure, un malfaisant qui avait suivi les rebelles en l'année Canh-thân (1740). Ceux-ci défaits, Chất auraient ramcuté des comparses ct sćvi sur Khoái-Châu'. Il est dit qu'en tous lieux, «ils incendient et saccagent. Tous les districts jusqu'à la frontière sur des milliers de lieues ont l'aspect d'une friche. Ils s'emparent des hommes et des femmes, jetent du grain à l'intérieur des yeux puis les recousent, ce qui est extrêmement cruel. Ils exigent une rançon de mille, dix-mille ligatures pour les libérer. Tous les nomment "les rebelles qui cousent les yeux" (phùng nhãn tặc). " ${ }^{10}$

De guerre lasse, des mandarins préconisèrent leur reddition. Le Seigneur, qui lui-même perdait espoir d'une solution rapide, se rallia à cette idée et songea à leur donner titres et terres. Or Chất refusa de disperser ses forces et finit par s'insurger de nouveau, s'empara de Khoái-Châu qu'il pilla. Trịnh Doanh dut envoyer ses généraux au $11^{\circ}$ mois 1743 qui vinrent à bout de l'insurgé lors d'une bataille à Đỗ-Xá ${ }^{11}$. À cette époque de crue du fleuve Nhị, bien avisé, le général en chef Đình Hoàn proposa de rompre la digue et faire se déverser les flots sur les hommes de Chất, ce à quoi le Seigneur ne consentit pas, ne voulant pas causer de préjudice aux districts environnants nous dit le Cuong muc. En 1744 (3 $3^{\mathrm{e}}$ mois), l'eunuque Hoàng Công Kỳ, nommé aux fonctions de gouverneur du Sơn-Nam en remplacement de Nguyễn Công Thái, tenta d'assainir la situation militaire. Fin stratège, aux mérites confirmés, il inspirait confiance aux soldats et dans un premier temps balaya les rebelles, rassérénant les populations (CM XL, 1). En $1745\left(12^{\mathrm{e}}\right.$ mois), alors que juché sur un éléphant et escorté de quelques dizaines de soldats il inspectait les

8. Entre autres appellations, signalons que le Binh Humg thuc luc tout comme le Curong muc qualifient Hoàng Công Chất de thảo tạc 草賊 qui est alors traduit en vietnamien par giăc co soit " pirate de brousse » ou «bandit de grand chemin ». Cette expression de thào tăc est fréquemment employée dans les annales que l'on retrouve dans le Đại việt sư ký toàn thur. L'expression de giăc biển « pirate de mer 》 était réservé à Nguyễn Hữu Cầu 阮有求, autre insurgé fameux de la même époque qui sévissait dans la région de Đồ-Sơn puis dans celle de Hải-Dương, avec lequel nous dit-on lloàng Công Chất était en liaison (CM XLI, 6 1751).

9. Khoái-Châu, préfecture du Sơn-Nam, puis du Sơn-Nam-Thượng à partir de 1741; par la suite les terres de Khoái-Châu formèrent la province de Hưng-Yên.

10. Binh Hurng Thurc Luc op. cit. cit. $\mathrm{f}^{\circ} 10 \mathrm{a}-\mathrm{b}$.

11. Đồ-xá (Đậu Xá) : village du huvện de Kim-động, province de Hưng-yên. 
remparts d'un fort nouvellement élevé, il tomba dans une embuscade montée par Chất. Hoàng Công Kỳ se refusa à baisser pavillon et périt. $(C M X L, 18)$

Nguyễn Hữu Cầu avait rejoint Chất après sa défaite de Bô-Đề en 1748. Ensemble ils s'emparèrent des huyện de Thần-Khê et Thanh-Quan. La chasse leur fut donnée par Phạm Đình Trọng et Hoàng Ngũ Phúc, la fine fleur des généraux de la Cour, qui fïrent subir à Hữu Cầu une lourde défaite sur les rivières Mã-Não et Hương-Nhi, le contraignant à fuir au Nghệ-An (où il fut pris en 1751). Quant à Chất, il aurait gagné le Thanh-Hoa car le Binh Hung thục luc nous apprend qu'il avait suivi les dénommés Tương, insurgé à Mỹ-Lương ${ }^{12}$, et surtout Vĩnh-Đồng ${ }^{13}$ du Sơn-Tây, or celui-ci était lié avec Lê Duy Mật. Ce premier indice nous permet de mettre en relation les deux hommes. À cette époque, 1751, Hoàng Công Chất se saisit d'un jésuite vietnamien et de cent chrétiens à l'ouest du Sơn-Nam. Il les libéra contre la fourniture par les missionnaires d'équipements mentionnés dans un mémoire ${ }^{14}$. Le texte nous indique ensuite qu'à la mort de Tương, soit en 1752, Chất « s'en retourna accompagné de plus de dix compagnons au Hưng-Hóa s'établir au động de MãnhThiên (soit Điện-Biên), puis (il) offrit sa reddition ». La Cour, qui venait de terminer la pacification du delta, aurait alors accepté et envoyé le comte de Trượng-Trung (?) pour rallier Chất et l'élever au titre de marquis de Khoản-Trung ${ }^{15}$. Mais celui-ci refusa, dit-on, dans des circonstances peu claires.

Entre 1751, où il s'enfuit au Thanh-Hoa, et sa réapparition dix ans plus tard dans le Hưng-Hóa, le Curong mục reste muet sur les agissements et l'implantation de Hoàng Công Chất. Seules les chroniques tai nous renseignent sur son parcours ${ }^{16}$. Elles nous indiquent qu'en $1754 \mathrm{Kinh}$ Thiên Chết a bâti une forteresse à Mường-Thanh (MãnhThiên) et aurait par la suite demandé à Bun Phanh, le chef de Mường-La (Sơn-La) de se mettre à son service. Devant le refus qui lui était opposé, Chất aurait mené ses troupes au combat à Cặm-Khắt (province de Sơn-La), contraignant Bun Phanh à quitter les abords de la rivière Noire pour un refuge dans les montagnes. Après quatre ans de guérilla (1758?), Chất aurait capturé Bun Phanh et sa famille dont il fít ses domestiques à Mường-Thanh. À cette période, le pouvoir de Chất s'étendait sur Mường-La (Sơn-La), Mường-Mụa (Mai-Sơn), Mường-Lò (Văn-Chấn), MườngCha (?). Il procéda à la nomination des chefs locaux qui lui versaient tribut. C'est

12. Mỹ-Lương : hụ̣̣̂̂n du phui de Quốc-Oai, province de Sơn-Tây, puis dans celle de Hà-Dông.

13. Vĩnh-Đồng : Commune du tông de Kim-Bôi, hutện de Mỹ-Lương, phì de Quóc-Oai, province de Sơn-Tây, puis de celle de Hà-Đông. C"est en cette contrée que s’enracina la révolte contre les Nguyễn menée par Cao Bá Quát en 1854.

14. Cf. Alain Forest, Les missionnaires fiançais an Tonkin et an Siam. wr/ et whr siècles. Paris, L'Harmattan, 1998, 3 vol. tome II, Histoires du Tonkin p. 93, note n 19, citant le document des archives des Missions Ftrangères AME 688 t $^{\circ} 265$ et 267.

15. Pour Hoàng C'ông C'hát, l'élévation au titre de marquis de Khoàn-Trung n'est pas aussi surprenante qu il y paraît de prime abord. ("était en quelque sorte une récompense aux soumissionnaires. et lhistoire montre qu'en bien des cas, elle ne laissait en rien présumer d'un ralliement durable, ni d'une absolution totale. Elle est souvent à comprendre comme une manceuvre dilatoire du pouvoir. Nguyễn llữu (ầu bénéficia en 1746 d’une offre semblable (marquis de Hương-nghĩa) accompagnée d'un commandement (Ninh dong tróng qucin) qu`il déclina (CM XL, 19). ('es pratiques n'allaient pas sans faire grincer les dents des généraux et, dans le cas précédent, suscitèrent l’ire mémorable de Phạm Đinh Trọng.

16. Đặng Nghiêm Vạn, Cầm Trọng, khả văn tiến, tông kim ân : Tur liệu vè lịch sir và xã hội dân tộc Thưi, Nhà Xuất Bản Khoa Học Xã Hội, 1977, 493 p. 
là un épisode peu clair sur lequel on aimerait en savoir plus. Hoàng Công Chất et le phia (hu se seraient alliés avec les Tai noirs pour repousser une invasion venue du Yunnan (ou du Laos selon les textes ${ }^{17}$ ). Leurs adversaires sont nommés Phé-co ou Phe-kiền et seraient des groupes Tay-thai au nord de Lai-Châu, vraisemblablement des Lü. Cet épisode, absent des textes mais attesté par les chants de la rivière Noire qui se sont transmis jusqu'à nos jours, est l'élément constitutif du culte rendu à Chất.

Les agissements de Chất ne défrayent plus la chronique jusqu'en 1761 lorsqu'il est mis en fuite et son associé Thành pris. Tout juste savons-nous «qu'une fois de plus, se prévalant d'un terrain difficile (Chất) s'est largement répandu, envahissant le territoire des dix châu" du Hưng-Hóa. Les chroniques lao indiquent pour l'année 1762 que «l'annamite Ong Chet vint s”installer à Quang Yang". À Viêng Xam Mứn, il avait élevé un camp fortifié sur l'emplacement d'une forteresse plus ancienne ${ }^{18}$ qui disposait de levées de terres ceinturées de douves ${ }^{19}$. De cette position centrale du Hưng-Hóa, il monta des expéditions jusqu'en 1767 sur le phù de An-Tây et toute la rivière Noire où les armées impériales appréhendaient de s'aventurer. C'est lorsque l'offensive de Lê Duy Mật et Hoàng Công Chất menaça les abords du delta que l'ultime opération de pacification de la province de Hưng-Hóa fut décidée.

Au début de l'année 1768, une expédition combinée des différents corps d'armée de Thanh-Hoa, Sơn-Tây et Hưng-Hóa fut envisagée. Nguyễn Đình Huấn, marquis de Huấn-Trung, en devint le commandant en chef (Kiêm-Thống-länh). Or l'homme, rigide et irascible, ne se distinguait pas en matière de stratégie; la logique des préséances de Cour doit expliquer cette nomination. Une impressionnante logistique fut alors établie permettant d'approvisionner une armée de 10000 hommes. Cent pirogues furent réquisitionnées sur la rivière Noire qui devaient mener hommes et matériel jusqu'à Vạn-Điền ${ }^{20} \mathrm{~d}$ 'où la route permet d'atteindre en dix jours le camp de Chất à Mường-Thanh. Le parcours complet prenait vingt-huit jours.

Le $9^{\circ}$ mois, la grande armée se mit en marche composée de cinquante unités militaires appartenant aux régions militaires du Thanh-Hoa et du Hưng-Hóa. Le premier détachement partit de sa province, l'armée du Hưng-Hóa de la capitale. Pourtant, de retards en délais, les troupes ne s'étaient pas encore mesurées à l'adversaire lorsque la nouvelle du décès du vieux rebelle prit la Cour de surprise. En lieu et place du soulagement de voir disparaître l'ennemi c'est la colère qui

17. Cầm Trọng, Cầm Quynh : Quám tó muớn - Trụện kể bàn Mrờng, Hanoi, Nhà Xuất Bản Sư Học. $58 \mathrm{p}$. Il s'agit de la traduction en vietnamien du texte Tai des chroniques des mucòng (Quám tó murón) de Mường Mười, chàu de Tuần Giáo, voir ici p. 44.

18. Forteresse dite trai ba van, i.e. 30000 meules à décortiquer le riz ou 30000 maisons, cf. Lê Quí Đôn (Kiến văn tiêu lục, trad. Viet. Viện sử học 1977, Réédition 1997 in Lê Qui Đôn toàn tập, t. II, Nhà Xuất Bản Khoa Học Xã Hội, Hanoi, 475 p. ; ici p. 306297.

19. Une recherche des vestiges de cette ancienne citadelle montre bien les restes de douves, qui forment maintenant une succession de bassins rectilignes au sud de Bản-Phü. On constate aussi que les terres aux abords de ces mares sont surélevées mais, étant désormais bâties, cultivées pour certaines d'entreelles, il reste très diffícile de déterminer l'aspect et même l'étendue de l'ancienne implantation.

20. Vạn-Điền : Vạn-Bờ peut être Vạn-Chò, en réalité Suối Rút, ce qui serait plus logique avec ChợBò, soit à $142 \mathrm{~km}$ de Hanoi. Phạm Thận Duật, (op. cit. p. 167) nous indique, en se basant sur le texte du Hung-Hóa lục, qu'en 1752 le thò-tiu du châu de Mộc. Xa Văn Ba. rassembla ce qui lui restait de troupes pour envahir le poste de Vạn-Chân. Lê Quí Đôn nous signale une contrée de ce nom dépendant du châu de Mai. (Kièn văn tièu lüce, op. c’it. ici p. 298) 
domina de le savoir parti de sa belle mort, privant la Cour de sa vengeance. Les généraux furent vertement tancés, Đình Huấn et ses lieutenants traités d'incapables et finalement relevés de leurs fonctions. Đoàn Nguyễn Thục, l'inspecteur aux armées auteur d'un réquisitoire implacable contre le chef des opérations le remplaça. Non seulement les impériaux avaient tergiversé et s'étaient cantonnés à Cổ-Pháp ${ }^{21}$, et refusant le combat, mais encore ils avaient pressuré la population de Việt-Châu22, lui soutirant du grain et des vivres, et réussissant à provoquer son exode. Or toute la tactique militaire reposait sur un acheminement constant et rapide de l'intendance qui ne pouvait être obtenu qu'avec le concours actif des villageois.

La Cour ignorait encore qu'une course de vitesse était engagée entre elle et Lê Duy Mật pour la possession de Mường-Thanh. À la mort de Hoàng Công Chất en $1768(2 / 2 / 1768)$, son fils Công Toản s'était autoproclamé archiduc (quóc công) (CM XLIII, 22) dans un contexte trouble où les généraux de Chất se livraient à une guerre de succession. Quelles qu'aient été les relations entre les deux vieux rebelles, faites d'intérêt commun et d'une certaine défiance, Chất disparu, la stratégie imposait à Lê Duy Mật de ne pas laisser son flanc nord à découvert. Du Trấn-Ninh, il dépêcha Miêu (ou Mẹo), son second, qui encercla à Thanh-Châu Đặng Đinh Gia, le général de Chất. Survint alors la mort de Miêu qui effrayait tant les généraux impériaux et, pendant l'hiver, l'assassinat de Đặng Đình Gia par le prénommé Vĩnh qui s'échappa au Trấn-Ninh. Le camp de Mường-Thanh se retrouva alors sans chef militaire de valeur.

Les événements se succédèrent alors très vite. Đoàn Nguyễn Thục fut officiellement chargé des opérations le $11^{\mathrm{C}}$ mois, jour Tân-họi (4/2/1769). En trois semaines, les officiers furent réaffectés et au $12^{\circ}$ mois Đoàn Nguyễn Thục conduisit l'armée aux abords de Thanh-Châu et livra un combat décisif à la rivière Nậm$\mathrm{Co}^{23}$. Attaqués par surprise sur plusieurs fronts, les rebelles retranchés dans des défilés furent anéantis en une journée de violents combats. Le $1^{\text {er }}$ mois du printemps de l'année Ki-siuu (1769), Nguyễn Thục entra à Thanh-Châu sans combat car les défenseurs avaient déserté la place deux jours auparavant et Hoàng Công Toản et ses affídés avaient pris la fuite en direction du Trấn-Ninh ( le BH dit Mang-Pồn).

Parti de Mang-Lâm ${ }^{24}$, le corps d'armée du Thanh-Hoa arriva par le Sud pour opérer sa jonction et trouva la besogne achevée. Restait à débusquer les fugitifs et à récupérer vivres et armement que recelait en abondance le fort précipitamment abandonné. À Thanh-Châu, Nguyễn Thục fít abattre les tours d'observation, raser les remparts et combler les fossés; il pardonna aux «égarés » et libéra les captifs.

21. Cò-Pháp : commune du iông de Thanh-Mai. hụ̂̀n de Tiên-Phong. phu de Quang-Oai, province de Sơn-Tây.

22. Việt-Châu : ou Mường (Mang) Việt, et le CM (IX, 29) nous précise qu'il s’agit de l’ancien ĐộngMán que la dynastie des Lê a transformé en Việt-Châu lequel deviendra après lè hụ̣̂̂n de Yên-Châu dans la provinec de llurng-Hóa et de nos jours de celle de Son-La. BK11-6a.

23. Nậm Co : le CM nous indique Thầm-C $\mathrm{C}$. Je suis tenté de croire que le terme vernaculaire a été traduit au $x x^{*}$ siècle (aucune confusion de caractère n'est possible), ce qui hélas ne permet pas de situer e lieu car. contrairement à l'usage, aucune note ne vient préciser la localisation de ce toponyme aussi cité dans Phạm Thận Duật Hemg Hóa Ki Lurọc, op. cit.

24. Mang-Lầm : cọng du chciu de Thuận, provine de Hưng-Hóa, à 13 jours de marche de la capitale nous dit Lê Quí Đôn qui nous signale que le thôn de Mai du district de Thuận est à deux veilles et demi de marche de Mường Lầm. L.ê Quí Dôn Kičn lẳn tièu lục, op. cit. ici p. 310. 
La population de vingt-trois villages ( au travail des rizières. Pour ce faire, les buffles et les boufs saisis chez les vaincus furent remis aux paysans. Puis on se mit activement à la recherche de la sépulture de Chất. Un homme reconnut le vieux manteau de guerre dont Chất se revêtait autrefois et immédiatement les ossements furent collectés, incinérés et les cendres dispersées. «Ce diable carbonisé pourrait encore coudre les yeux des gens! " s'exclama un soldat. En le jour Bính-thân, (21/3/69) Thục ramena les troupes à la capitale et fit un rapport détaillé sur l'état de relâchement des liens entre les peuples tributaires et la Cour, insistant sur la nécessité d'y remettre bon ordre.

On pouvait croire l'affaire terminée mais, dans ces récits de pacification des régions lointaines, les retournements de situation sont fréquents car, battu, l'ennemi s'enfuit et regroupe ses forces dans quelque village reculé. Ne pouvant leur donner la chasse indéfiniment, les armées impériales rechignaient à s'attarder sur place, redoutant plus les miasmes que les ennemis. Immanquablement, après avoir été fragmentées, les bandes se reconstituaient. À peine les troupes étaient-elles revenues à la capitale qu'un mois plus tard, Xa Văn Ba chef de Mộc-Châu rassemblait les survivants de Thanh-Châu qui pillèrent le châu et envahirent le poste de Vạn-Điền. Đoàn Nguyễn Thục, derechef Commandant des opérations, mena une nouvelle armée de dix régiments qui progressa en deux colonnes par Mai-Châu et ThanhChâu. Ils mirent plus de dix jours pour parvenir à Trình-Hằng ${ }^{25}$ et les mettre en fuite. Xa Văn Phương emmena de nouveau les populations des châu présenter leur reddition. La campagne, après ce dernier soubresaut, prit véritablement fin. Le $4^{\circ}$ mois, Đoàn Nguyễn Thục demanda à dire adieu aux armes, priant qu'on le laisse porter pleinement le deuil de sa mère. Le Seigneur entendit sa demande. On passa à l'attribution des mérites et des blâmes (26/7/69).

Hoàng Công Toan, le fils de Chất en fuite au Trấn-Ninh, n'y resta pas et se réfugia au Yunnan où il fut hébergé par le gouverneur de la province, d'autant plus facilement qu'il lui aurait cédé des territoires pour prix de son aide ${ }^{26}$. Quant à Lê Duy Mật, il ne désespéra pas de reprendre Mường-Thanh et avait été rejoint par les débris de la bande de Chất. Au $8^{\circ}$ mois 1769 , ils furent battus par les unités de l'armée du Hưng-Hóa que. cette fois, on avait pris soin de laisser dans les parages. Le $26^{\mathrm{c}}$ jour du $11^{\mathrm{c}}$ mois 1769 , Hoàng Đình Thể mandaté par la Cour, parvint à obtenir le retour des compagnons de Chất réfugiés en territoires laotien et chinois et qui constituaient une menace potentielle. Par l'intermédiaire des chefs locaux, et en particulier du thổ-mục de Chiêu-Tấn, Điêu Chính Văn, la Cour leur avait fait parvenir une offre de pardon, 450 d'entre eux se rendirent. Ce n'est que bien plus tard, le $21^{\mathrm{C}}$ jour du $1^{\mathrm{er}}$ mois 1770 que la rébellion trouva son réel épilogue lorsque les derniers tenants de Chất furent définitivement mis en déroute ou tués près de la frontière de Chine dans le châu de Quảng-Lăng ${ }^{27}$ qui fut alors pacifié. Mường

25. Trình-Hằng : nom d'un mương du châu de Mộc. À treize jours de marche de An-Trường et 11 de Mường Thanh. Lê Quí Đôn Kiến văn tiều lục. op. cit p. 329.

26. Cî. Nguyễn Khắc Xương "Về vùng đất đai phù An Tây, trấn Hưng-Hóa thời Lê mạt", in Nghiên cirulich sie, 1985, n²20. p. 42-47.

27. Quáng-Lăng ou encore Mường La, châu de la région frontalière maintenant au Yunnan, un des six châu du phu de An-Tây perdu au xvıı" siècle. On y accédait par la Nậm-Na. 
Thanh prit officiellement en 1775 le nom de Ninh Biên avant que de devenir, en 1841, la préfecture (phii) de Điện Biên.

Il faut noter que les textes des annales historiques, tant de l'époque des Lê que de celle des Nguyễn, font porter sur Hoàng Công Toản la responsabilité de la perte des six districts frontaliers qui furent dès lors intégrés au territoire chinois. Du point de vue de l'analyse historique, constatons que si le père est présenté comme un défenseur de l'intégrité du territoire national, le fills est, lui, voué aux gémonies.

\section{Hoàng Công Chất maître de conférences, l'aventurier mythifié}

La vallée de Điện Biên ne manque pas de légendes dont les plus anciennes sont liées aux mythes fondateurs des peuples Tai et Lao, autochtones donc, et pour les textes de Cour remontent au $\mathrm{xI}^{\mathrm{C}}$ siècle ${ }^{28}$. Le temple de Hoàng Công Chất, sis dans la commune de Noọng Hẹt au sud de Mường-Thanh, est quant à lui un hommage appuyé à un personnage de l'ethnie Kinh (et à ses compagnons ${ }^{29}$ ) pour avoir su efficacement apporter son concours aux chefs tai en lutte contre l'invasion des «Phẻ » (vraisemblablement des Lü) ${ }^{30}$. S'il faut en croire la stèle, ensemble, ils auraient triomphé et mis en déroute 9000 ennemis vers le Laos au $5^{\circ}$ mois de 1754. Les faits sont corroborés par les chroniques tai des muròng de la rivière Noire. Trois siècles après, ce n'est pas le rebelle à l'autorité de l'État ou le soutien des souverains Lê qui est célébré mais l'allié de circonstance des populations locales. L'insurgé du delta, rompu au combat, aurait en bon aventurier su saisir l'occasion qui se présentait car rien n'indique qu'il avait pu remonter du Thanh-Hoá avec un groupe de plus de dix hommes.

On le voit, la part du mythe dépasse de beaucoup les données assez partielles dont nous disposons. Sur sa mort courent les histoires les plus fantasques. Certaines légendes locales ${ }^{31}$ racontent que la Cour envoya un émissaire rallier Hoàng Công Chất qu'il aurait rencontré sur la colline Lạn Trợng ${ }^{32}$. Chất, rejetant l'édit, l'aurait alors renvoyé. Le lendemain, $25^{c}$ jour du $2^{c}$ mois lunaire, il fit abattre des boufs en nombre pour un grand festin puis, repu et ivre, sauta sur la poudrière avec ses

28. Cf. Phan Kiến Giang "Mường Thanh - Vung huyền thoại" (Mường Thanh terre de légendes), in Vün hóa và lịch sit ngurời thái ơ Vị̣t $\mathrm{Nam}$. Ouvrage collectif, 63 articles. Hà Nội. 1998. Nhà xuât bạn văn hóa dân tộc, 696 p. p. 374-381.

29. Le nom de ces commandants (Quạm), compagnons de Chầt, sont les suivants : Quận Ngai, Quận Tả, Quận Hữu. Quận Xiêm, Quận (hung, Quận Khanh. (li. đặng Nghiêm Vạn, (ầm Trọng, "Những

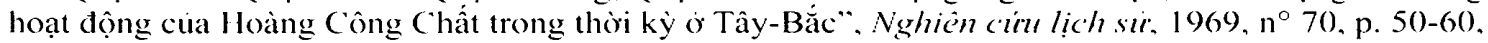
ici p. 52 .

30. Sur les méfaits des envahisseurs « Phe » voici ci qui peut être lu sur le site de l'agence vietnamienne d'information sans la moindre mention de souree: "In the early. rears of the / 8 th century the' Phe bandits did terrible things to the people of Dien Bien. Those barbarians tossed children on a small plain at the foot of Lap Hill. and then flooded the area with water: When the plain dried ap), all that was left of the children were their bones, thousands of them. littering the land. And so now we call the plain Tong Khao, or White Bonc'. VNA. The valley of immortal souls, 3 mai 2004, signé Dao Trong Khanh.

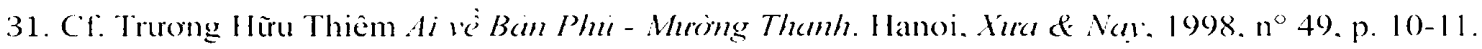

32. Il sagit de l’éminence de Lang (hurơng (Pu Lang (hương) nom d’un che la Tai qui bouta les l.ü dans des temps reculés et qui. jadis, y aurait installé son campement, aussi nommée Kiêng Ki An, en fait depuis 1953 la colline baptisée $\Lambda 1$ par les Vietnamiens et Eliane 2 par les lrançais. 
généraux et provoqua l'explosion fatale ${ }^{33}$. On le constate ici, les faits évoqués sont en tous points analogues au suicide de Lê Duy Mật ${ }^{34}$. La confusion, si elle n'est certaine, est rendue fort probable par les similitudes de détail. Les chroniques tai de la région amalgament d'ailleurs les deux révoltés dans une histoire commune. Tous deux hommes du delta, entretenant des liens sur des territoires adjacents, ils avaient subjugué les populations des Tai-Lao à la même époque et se retrouvent logiquement ensemble, dans une histoire écrite lacunaire, volontiers portée sur l'épopée.

Les légendes, chants et histoires colportés sur le personnage sont très éloignés de ce qu'en disent les récits vietnamiens. Les textes antérieurs au $\mathrm{xx}^{\mathrm{C}}$ siècle voient en lui, tantôt un rebelle, tantôt l'auteur d'un soulèvement pour une juste cause (nghĩa quân), mais nullement le modèle d'une symbiose interethnique. Comment alors expliquer son rôle actuel de figure emblématique de l'union des peuples pour la défense du territoire national? Deux points de vue sont à dissocier, celui des autorités locales qui agissent avec l'accord du gouvernement central et celui propre des populations tai, sur lequel il serait utile d'enquêter plus avant. Ce dernier privilégie l'idée que le pouvoir de Keo Chất (Chất le Kinh) s'étendait de la rivière Noire à la rivière Mà et jusqu'en Chine avec Mường-Thanh comme capitale. C'est en quelque sorte une réminiscence de l'indépendance de fait dont bénéficiait jadis la zone du Nord-Ouest. Hoàng Công Chất est alors perçu comme un héros purement local, régnant sans partage sur le plus vaste territoire et symbolisant l'unité entre mường. En témoigne ce morceau d'épopée chantée par les Tai de la rivière Noire que nous cite Cầm Trọng :

« Voyez, en bas est un roi,

En nos hautes terres un seigneur

Les régions de Mường Puồn, Châu Ét

Depuis Đà-Bắc et Chợ-Bờ

Jusqu'à Châu So et Là en amont

Tous se sont rendus au seigneur de Mường Thanh » 35

33. Le Binh Hung Thưc Luc (op. cit. ici f 10-b) est plus lapidaire : "(Chất) apprit alors l'arrivée de la grande armée. en fut épouvanté et mourut. Les populations barbares (Man) se hâtèrent de l'annoncer le long des routes et, à cette nouvelle, tous expriment le vif ressentiment que l'on ne soit point arrivé à temps pour lui infliger la peine capitale $\gg$.

34. La mort de Lê Duy Mật est datée du $22^{\circ}$ jour du $2^{\mathrm{e}}$ mois 1770 . Encerclé dans son bastion de TrìnhQuang, promis à une défaite imminente, le prince Mật, femmes et enfants ainsi que sept complices, (Đài, Hào, Nhiệm. Uyên. Vĩnh, Thìn), se regroupèrent dans la demeure, déployèrent une natte sur un monceau de poudre et toute la journée s'enivrèrent en silence. À la veille tuât (19-21 heures), alors que les impériaux s`apprêtaient à lancer l'assaut final, le palais ennemi s'embrasa soudain, des flammes s'élevèrent dans le ciel dans une succession d'explosions. Cf. Binh Ninh Thurc Lục. Récit officiel de la pacification par les Trịnh du soulèvement du prince Lê Duy Mật au Trấn-Ninh, 1769-1770. Ouvrage commandé par Trịnh Sâm. En Hán, Paris, Société Asiatique, fonds Henri Maspero HM 2211109 p; Hanoi, Institut Hán-Nôm. VHv 2339, manus., 28,5 x 16,6, 109 p.

35. Cầm Trọng, Ngurời Thái ơ Tầ Bắc Việt Nam. Hanoi, 1978. Nhà Xuất Bản Khoa Học Xã Hội, 597 p. Cit. p. 325. Ajoutons que Mường Puồn est probablement Xieng Khuang et Châu Ét Sầm Nưa. que Đà-Bắc et le marché de Bò sont sur le cours inférieur de la rivière Noire, près de sa confluence avec le fleuve Rouge. Chàu So (Mường So Phong-Thố) et (Mường) Là se situent tout deux à la frontière chinoise, en territoire vietnamien pour le premier. chinois pour le second. 
Pour la vision de la capitale, sans doute faut-il faire la part des différentes phases de relecture de l'histoire vietnamienne. Dans un premier temps, au XIX ${ }^{\mathrm{c}}$ siècle, les annales impériales de la dynastie des Nguyễn réhabilitent le "rebelle " dans sa qualité de combattant légitimiste pour le rétablissement de la dynastie des Lê, sans pour autant l'absoudre des exactions commises ni nier son rôle dans les pertes territoriales consécutives à son insurrection. Dans un second temps, les historiens vietnamiens du $\mathrm{xx}^{\mathrm{C}}$ siècle font un parallèle implicite et fort à propos avec les événements survenus à Điện-Biên en 1954. Ils érigent Hoàng Công Chất en précurseur d'un front sacré unissant les peuples Kinh et Tai contre les envahisseurs. L'homme que les textes nomment «celui qui coud les yeux des gens », et dont les missionnaires, peu sujets à des a priori dynastiques, notaient qu'il écumait leurs chrétientés du Thanh-Hoá et enlevait leurs ouailles contre rançon, (ce que sousentend aussi Phạm Đình Hổ ${ }^{36}$ ), celui-là même qui asservissait les seigneurs Tai de Sơn-La, comme l'évoquent les chroniques locales, devenu prérévolutionnaire, disparaît au service d'un dessein politique qui transcende sa personne ${ }^{37}$. L'étude de la biographie lissée de Hoàng Công Chất ne relève donc plus de l'histoire mais bien de la téléologie appliquée à l'image du héros ${ }^{38}$.

\section{De l'analyse à la réécriture}

Soucieux de sortir de la gangue événementielle de l'histoire classique qui faisait la part belle à l'aristocratie, dès 1955 les chercheurs vietnamiens se sont attelés à la tâche de distinguer les insurrections paysannes de celles ayant d'autres motifs : brigandages, ambitions politiques voire mouvements messianiques ${ }^{39}$. Cette entreprise menée par les chercheurs de l'Institut d'histoire de Hanoi et initiée dans la revue Littérature Histoire et Géographie (Văn sü địa) tendait à mettre en évidence les carences du système précolonial, dit "féodal " (même si le terme est discutable, voir impropre), et de lier ainsi l'émergence des jacqueries au régime de la propriété foncière. L'accaparement indu des terres communales (au profit des mandarins ou pour alimenter l'armée) est livré comme le moteur du ressentiment populaire dont la rébellion constitue le dernier avatar. Minorant l'hypothèse d'une crise de régime, on considère que c'est le système lui-même qui était en crise. La révolte paysanne, phénomène spontané, apparaît comme socialement justifiée car générée par l'injustice intrinsèque du système féodal. En pratique, de nombreux rebelles sont réhabilités sur l'autel de la démocratie villageoise et font l'objet d'une

36. Phạm Dinh Hồ Vù trung tị̂ büt (Au fîl du pinceau par temps de pluie), écrit entre 1789 et 1802. Réed. Hà Nội. NXB Văn Học, 1972, 215 p. : cf. p. 150.

37. Cf. Đặng Nghiêm Vạn. (ầm Trọng: "Những hoạt động cua Hoàng Công Chát trong thời kỳ ơ Tây-Bắc", (les activités de Hoàng Văn ('hất à son époque au Nord-Ouest) Nghièn ciún lịch sir. 1965. $\mathrm{n}^{\circ} 70$, p. 50-60.

38. Cf. Lestude de Benoit de Tréglodé Itiros et Révolution an Viét Nam. Paris. L'Harmattan, 2001. 444 p. ici p. 222-223.

39. Je me réfëre à l'article de Nguyễn Dồng Chi intitulé : "Vai trò cua đằng cấp và giai cấp trong các phong trào khơi nghĩa nông dân và chiến tranh nông dân ờ nưa đầu thế ký XVI và giữa thế ký thứ XVIII “ in Nghic'n cirn lich sir, 1964, n 60, p. 19-26. 
classification qui prélude à l'émergence d'une image du paysan sans terre en lutte contre l'arbitraire et les privilèges.

Ces recherches se heurtent, et c'est hélas la règle, aux carences de la documentation. Les compilateurs des annales impériales, du Curong muc par exemple, ne s'étendaient pas sur les tenants et aboutissants de ces révoltes, ces sources sont par conséquent de peu d'usage. Et pourtant, en se basant sur ces textes peu prolixes, on en est venu à rechercher l'extraction sociale des meneurs. De la sorte certains furent qualifiés d'intellectuels ou d'aristocrates. Toutefois, pour Nguyễn Đồng Chi, dans onze rebellions sur dix-sept, l'origine paysanne des mouvements insurrectionnels est mise en évidence. La place est faible pour les insurrections aristocratiques, celle de Lê Duy Mật (1738-1770) fait donc figure d'anomalie ${ }^{40}$.

Cette requalification des faits s'opère à la seule lumière de l'origine paysanne des insurgés considérée comme critère par défaut. D'autres motifs auraient pu être évoqués, y compris le simple brigandage, mais ils sont évacués au profit d'une noble figure du paysan révolté dont on présume a posteriori des motivations. Or la presque intégralité de la société vietnamienne était alors paysanne. Les soldats d'élite restaient des soldats-paysans du Nghệ-An ou du Thanh-Hoá qui, eux aussi soumis aux abus de l'exploitation foncière, n'étaient pas non plus épargnés par les calamités. Pourtant ces régions restaient calmes et passaient pour les soutiens du régime. Cette question de la localisation des rébellions, que l'on souhaiterait mettre en rapport avec les inégalités de la question agraire n'est pas résolue faute de sources riches et suffisantes et ceci bien que des cartes aient été dressées ${ }^{41}$. Il ressort néanmoins du débat mené à Hanoi que la révolte populaire des temps " féodaux » est donnée comme une manifestation ultime, vouée à l'échec faute de véritable projet politique.

Dans le cas qui nous intéresse, la grille d'analyse ainsi bâtie s'applique mal. Le paysan révolté est censé «prendre aux riches pour distribuer aux pauvres », selon une formule souvent employée pour Nguyễn Hữu Cầu ou les Tây-Sơn, mais Hoàng Công Chất n'est jamais présenté sous cet angle. On ne trouve nulle mention d'une redistribution des terres ou d'une mise à bas de l'appareil " féodal ». Le système des mường qui prévaut dans le bassin de la rivière Noire reste inchangé et conserve ses chefs héréditaires (si féodalisme il y avait, c'était déjà bien dans les marges frontalières). La volonté de calquer un schéma de lutte des classes est contredite par de criants symboles. Chất, à l'instar des plus puissants des chefs de bandes, tels Nguyễn Danh Phương et Lê Duy Mật, est en quête de légitimité. Une fois son pouvoir ancré sur un territoire, il se pare de titres de Cour, procède à l'édification d'un palais et cède à la tentation d'un pouvoir qui, lui aussi, se caractérise par l'appropriation de la terre. Ces éléments semblent indiquer que les ambitions personnelles, patentes

40. Cf. l'article de Nguyễn Văn Huyên. "Cuộc khởi nghĩa Lê Duy Mạt (1738-1770) có phai là cuộc khời nghĩa nông dân không ?" Hanoi, Nghiên cíu lịch sit, 1965, n 81 p. 44-49. L'auteur s'efforce de déterminer si l'insurrection de Lê Duy Mật relève d'une lutte entre factions répondant d'un même ordre féodal, ou si l'implication des soldats, d'essence paysanne, la qualifie comme mouvement populaire. Il conclut que non.

41. Pour une cartographie des rébellions du xv!l" siècle voir : Nguyễn Hải Yến. Phan Ngọc Liên.

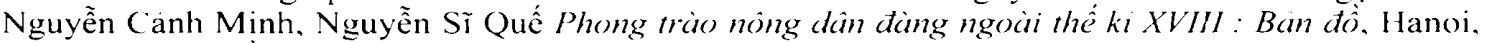
Trung tâm bản đồ và tranh ảnh giáo dục, 2002 . Une carte en couleur de format $66 \times 100 \mathrm{~cm}$. L insurrection de Hoàng C'ông ('hất est à l'échelle 1:1.750.000. 
pour le prince des Lê mais non moins notoires chez les autres, prenaient facilement le pas sur les principes égalitaires. Fallait-il pour autant voir dans ces manifestations le «stade infantile» des révoltes sans idéologie formée ? On pourrait aussi arguer que ce n'est pas tant le système dans son principe qui est critiqué mais la place qu'y occupent les révoltés, fussent-ils paysans, qui lorsque l'occasion se présente recréent un système en tout point identique dont ils ont le contrôle.

Un autre point faible de cette idéologie progressiste appliquée aux mouvements insurrectionnels réside dans l'articulation des rébellions paysannes avec le mouvement national. Comme le souligne Nguyễn Xuân Linh, une tendance existe qui vise à "dénier tout fondement aux soulèvements dirigés par les chefs de minorités contre le pouvoir central, puisque (...) ils représentent un danger pour l'union nationale". Pour les soulèvements des zones frontières, la distinction est délicate et réglée au cas par cas. L'origine deltaïque de Hoàng Công Chất vient à point nommé rassurer sur ce point.

Dans un article commun publié en 1965, Đặng Nghiêm Vạn et Cầm Trọng, le Việt et le Tai, peuvent donc établir les faits de la manière suivante : «On peut dire que l'action de Hoàng Công Chất donne une belle image du sentiment de solidarité entre les peuples du Nord-Ouest et le peuple viẹt dans la résistance à l'invasion étrangère et contre la cour féodale du Vietnam. [...] maintenant se tient un débat sur les mouvements insurrectionnels paysans. En se basant sur la documentation faite d histoires manuscrites et des légendes du peuple Tai, nous voudrions entamer. une présentation sur quelques traits de l'action du héros paysan Hoàng Công Chát (vị anh hùng nông dân) survenus au Nord-Ouest afin que le lecteur puisse se documenter, et nous souhaitons ardemment que les lecteurs, surtout les natifs du Nord-Ouest ou ceux qui y travaillent, puissent remédier aux insuffisances. " ${ }^{42}$

En résumé, l'extraction de Hoàng Công Chất, révolté Việt d'origine paysanne, remplit les critères de légitimité aux yeux des chercheurs vietnamiens qui établirent le credo historique sur les insurrections paysannes dans la revue Études Historiques (Nghiên ciú lich sü) entre 1960 et 1970 . S'étant établi à Điện-Biên, il s'y serait fortifié et, liguant avec lui les chefs locaux, Tai et Lao, aurait victorieusement repoussé une invasion des Phé venue de l'ouest. C'est en substance ce que retient la stèle du temple dédié à Chất. Deux siècles et demi plus tard, il est aisé d'en conclure que c'est donc sous la direction éclairée d'un homme du delta que les populations locales ont été en mesure d'affermir les frontières nationales. Le parallèle avec la bataille de 1954 est posé.

Lorsque fut traduit et publié en 1989 le Hung-Hó ky luroce, une monographie régionale de Phạm Thận Duật écrite au XIX" siècle, une note des traducteurs fut rajoutée par Ngô Thế Long. Elle met en garde le lecteur: malgré l'intérêt incontestable de ce texte d'époque, les critiques du mandarin envers la rébellion de Hoàng Công Chất sont absolument infondées. S'agissant d'un " soulèvement populaire ", il est donc regrettable que le terme de giăc (rebelle) soit employé dans le texte ${ }^{43}$. L'histoire étant revisitée, les qualificatifs précisés, la voie est alors ouverte

42. ( 'f. Đặng Nghiêm Vạn, Cà̀m Trọng: "Những hoạt dộng cua Hoàng C'ông Chất trong thời kỳ ơ TâyBắc". Nghièn cinu lich sir, 1965, no 70, p. 50-60.

43. Ngô Thế Long, note de prèsentation du texte Hung Hóa Ki Lự̛̣ de Phạm Thận Duật in Phụm Thụin

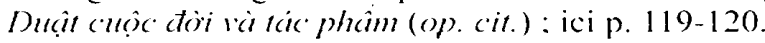


à une sanctification de l'effigie du héros. La création d'une figure emblématique. somme toute consensuelle, entre les Việt, garants de l'intégrité du territoire national, et peuples minoritaires du bassin de la rivière Đà, alors zone autonome (jusqu'en 1975), s'intègre à point nommé dans une longue tradition de héros nationaux, mais aussi locaux, avalisés par le pouvoir.

\section{Une histoire simplifiée qui confine au conte}

Du petit temple rebâti par la population en 1936 (dont seul un texte fait mention ${ }^{44}$ ) il ne restait dans les années soixante au mieux que des vestiges, la cloche d'origine ayant depuis longtemps disparu. On imagine mal que le culte ait pu être autorisé à l'époque où, partout dans le Nord du pays, la lutte contre les superstitions faisait rage avec son corollaire de destruction de lieux de culte. C'est donc bien plus tard que l'édifíce fùt reconstruit, puis inscrit sur la liste des monuments historiques en 1981. Enfin le portrait de Hoàng Công Chất fut transféré de la pagode Bồ-Xuyên de Thái-Bình ${ }^{45}$ vers Điện-Biên le 20 septembre 1996. La date des festivitćs annuclles a été fixée au $25^{\circ}$ jour du $2^{\circ}$ mois lunaire soit la date anniversaire présumée de la mort de Hoàng Công Chất. Le petit temple a été récemment agrandi. la stèle refaite (qui élude tout de l'action de Chất dans le delta) et une cloche fondue peu avant les célébrations qui marquèrent le cinquantenaire de la victoire vietnamienne de ĐiệnBiên-Phủ.

À l'intérieur du temple, placé en hauteur sur le mur de la travée de droite, un certificat délivré par les autorités centrales, ici le ministère de la Culture et de l'Information, atteste de la reconnaissance officielle du lieu en $1992^{46}$. On y lit: «Le titre de site culturel est conféré au temple de Hoàng Công Chất, auteur d'un mouvement insurrectionnel légitime du XVIII" siècle ». Le certificat reste dans sa forme très laïc mais, à un mètre, le règlement intérieur du temple complète immédiatement cette impression en mentionnant le mot thánh (saint). Le passage au domaine religieux est bien entériné. 11 s'agit, en quelque sort d'un « classement » civil doublé d'une composante religieuse qui n'est pas sans évoquer les sắc phong ou brevets d'élévation des divinités de l'époque impériale.

La question reste cependant entière, dans un pays où peu de choses se font hors du contrôle des autorités, à qui doit-on la promotion d'un aussi important centre culturel/cultuel ? De toute évidence, l'investissement dépasse les possibilités d'un évergétisme à caractère individuel. Doit-on attribuer cette initiative à l'État, aux collectivités locales ou à un généreux mécène ? Sans doute aux trois. En 1994, l'État a contribué à hauteur de 70 millions de đồng (soit 7000 \$) à la reconstruction et la

44. C'f. Trương Hữu Thiêm Ai vè̀ Bä Phi - Muòng Thanh. Hanoi, Xura \& Nạ, 1998, n 49, p.10-11.

45. Renseignements pris. le đỉnh du village de Bồ-Xuyên de Thái-Bình (jadis tông Lạc Đạo, hự̣̂n Vũ Tiên. maintenant xã Lạc Đạo, huyện Vũ Thư) honore comme thành hoàng Trần Mỉnh Công, aucune mention n’est faite de Hoàng Công Chât. C'f. Ngô Đức Thọ (ed) Di tich lịch sur iăn hóa Việt Nam. Hanoi. 1990, p.105.

46. Qui est de touté évidence la confirmation d'une décision antérieure datée du 9 février 1981 , "inscription comme site historique et culturel $n^{\circ} 159 »$. 
restauration de la stèle ${ }^{47}$. Sur un des murs du temple, un panneau de grande taille célèbre les mérites de la divinité au nom du clan Vũ de Hải-Phòng ${ }^{48}$. Une devise en lettres d'or sur fond rouge s'étale en deux heptasyllabes tài năng vang dọi khắp non sông, dî́c dộ ghi sâu lòng dân tộ [talent retentissant partout dans le pays, grandeur d'âme profondément inscrite dans le cour du peuple]. Un don a-t-il été effectué, ce dont le panneau attesterait comme une figure moderne des stèles de donation de jadis ? Quel rapport le clan Vũ de Hải-Phòng entretient-il avec le culte de Hoàng Công Chất alors que dans le canton d'origine des Vũ seul Ngô Vương Quyền est honoré ? Le rapport est-il historique ou le clan Vũ s'est-il implanté à Điện-Biên? Pour l'heure nous n'en savons pas plus. Cette étude des donateurs des pagodes et des temples, par le passé comme de nos jours, reste à faire et viendrait fort à propos éclairer le sens des nombreuses stèles. Interrogés, les gens du cru indiquent que les travaux de réfection du temple seraient à mettre au compte de l'initiative privée d'un lointain descendant disposant de moyens conséquents. Or, s'il faut s'en remettre aux textes des annales impériales, la descendance directe de Chất, son fỉls Toän, s'est jadis réfugié en Chine. Peut-être alors s'agit-il de quelques collatéraux ou même d'un natif de son village d'origine dont il est la seule figure remarquable. Une prochaine visite dans son lieu de naissance apportera, il faut le souhaiter, l'explication attendue.

Par contre, la présence des huit sentences en caractères nôm sur fond or qui doublent les piliers du temple suscite d'autres interrogations. Elles sont manifestement neuves et ne peuvent être la reproduction d'anciennes sentences puisqu'il n'y avait plus de temple pendant près d'un siècle. Le nôm est affaire de spécialistes, lesquels sont rares. La création de sentences en caractères, que rien ne justifie si ce n'est la patine de l'ancien, l'usage des caractères, nôm de surcroît pour renforcer le côté national et proprement vietnamien, sont quelque peu surprenants. Et l'on se prend à imaginer qu'une telle action, pensée et financée, n'est pas due au hasard mais s'insère dans un dispositif plus large lié au contexte de renaissance des cultes « utiles » dont la portée politique est facilement perceptible.

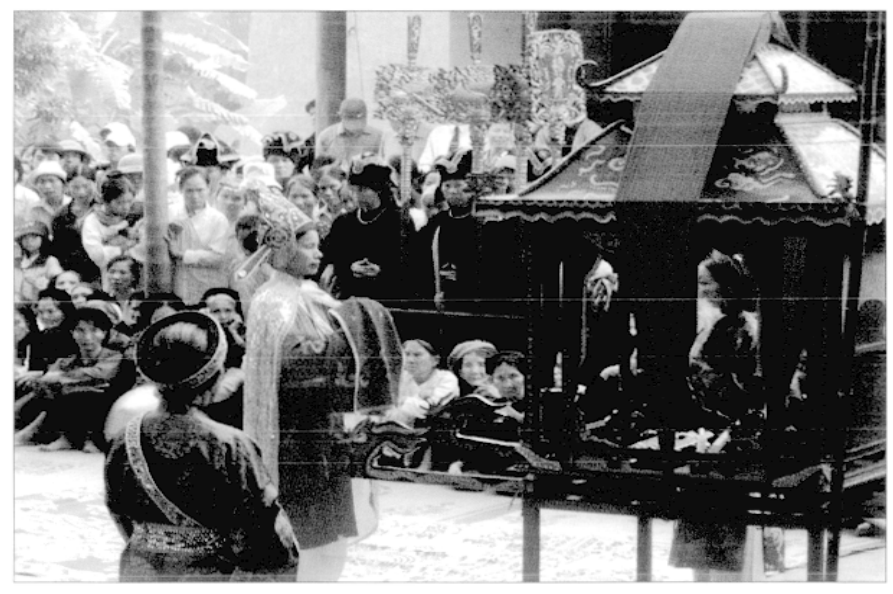

Fig. 1

47. Nguyễn Như Ý. Nguyễn Thành Chương. Bùi Thiết Tur điền dịa danh Văn hơa và thắng cănh Việt Nam, Hanoi, NXB Khoa Học Xã Hội, 2003. cf. p. 113.

48. Le panneau mentionne: Họ Vü Trung Hành, Đàng Làm, quận Haii An. Haii Phòng, tương nhó urớng quân Hoc̀ng Công Chât [La famille Vũ (de l'ancienne commune de) Trung-Hành. (canton de ?) Đàng-Lâm, arrondissement de Hai-An, (ville de) Hai-Phòng, commémore le général d'armée lloàng Công Chất]. 


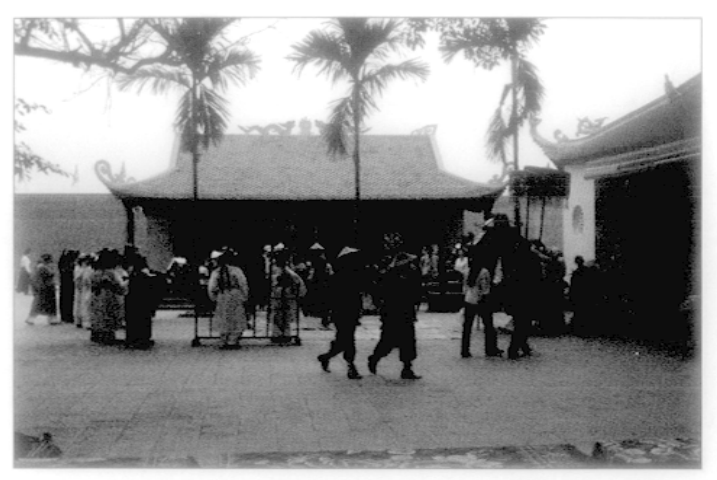

Fig. 2

Fig. 1 et 2 : Cérémonie dédiée à Hoàng Công Chất, citadelle de Bàn Phù, province de Điện-Bièn-Phú. Clichés : Ph. Le Failler, avril 2005.

\section{BIBLIOGRAPHIE}

\section{CÂM TRONG}

1978 Ngươi Thái ở Tây Bắc Việt Nam (Les Thai au nord-ouest du Vietnam) Hanoi, Nhà Xuất Bản Khoa Học Xã Hội, 597 p.

CÀM TRỌNG, CÀ̀M QUYNH

1960 Quám tố mướn - Truyện kể hản Mường (histoire des villages des mường) Hanoi, Nhà Xuất Bản Sử Học, 58 p.

ĐĀNG NGHIÊM VAN

1986 "Hoàng Công Chất một tấm gương đoàn kết dân tộc bảo vệ biên cương tổ quốc Việt Nam" (Hoàng Công Chất un exemple de solidarité populaire pour la défense des frontières nationales du Vietnam) in Phạm Thị Nết, Trương Sỹ Hùng, Bùi Duy Lan, Đặng Nghiêm Vạn, Đỗ Phú Hứa, Nguyễn Tuấn Lương : Danh nhân Thái Bình. vol.1 : Sở văn hoá và thông tin Thái Bình, 261 p., Notice sur Hoàng Công Chất p. 93-109.

1987 "Vê vai trò của Chúa đất trong xã hội tồn tại chế độ Thổ ty, Lang đạo, Phìa tạo, Chúa dất cuối thế kỷ XIX - đầu thế kỷ XX" (Le rôle des propriétaires terriens dans la société sous le système des seigneuries héréditaires, chefs montagnards, classes dominantes et propriétaires fonciers, fin XIX ${ }^{\mathrm{C}}$-début xx ${ }^{\mathrm{e}}$ siècle), Hanoi, Nghiên cúu lịch sü, 1987, 5-6, p. 29-34.

ĐẬNG NGHIÊM VẠN, CẦM TRỌNG

1965 "Những hoạt động của Hoàng Công Chất trong thời kỳ ở Tây-Bắc" (les activités de Hoàng Văn Chất à son époque au Nord-Ouest), Hanoi, Nghiên cíu lich sủ $\mathrm{n}^{\circ} 70$, p. 50-60.

ĐẬNG NGHIẾM VẠN, ĐINH XUÂN LÂM

1979 Điện Biên trong lịch sìr. (Điện-Biên dans l'histoire) Nxb Khoa học xã hội, 1979. - $253 \mathrm{p}$.

\section{ĐÕ VĂN NINH}

1998 "Thành Bản Phủ" (la citadelle de Bản Phú), Hanoi, Nhũng phát hiện mới về khào cồ hoc năm 1/1991, p. 31-41.

FOREST, Alain

1998 Les missionnaires français an Tonkin et an Siam - XVII et XVIIIe siècles. Analyse d'un relatif succès et d'un total échec. Paris, L'Harmattan 3 vol: I. Histoire du Siam, 462 p. ; II. Histoire du Tonkin, 302 p. ; III. Organiser une Église, convertir les infidèles, $494 \mathrm{p}$. 
GASPARIONNN:, Émile

1939 «Annamites et Thai au Xve siècle », Journal Asiatique, p. 405-436.

LÊ QUí ĐÔN

1777 Kién văn tiếu lục (notes des choses vues et entendues), trad. vietnamienne Viện sử học 1977, Réédition 1997 in Lê Qui Đôn tocàn tập, t. II, Hanoi, Nhà Xuất Bản Khoa Học Xã Hội, 475 p.

NGÔ ĐÜC THỌ (éd.)

1990 Di tích lịch sir văn hóa Việt Nam (Vestiges historiques et culturels vietnamiens) Hanoi, Nhà Xuất Bản Khoa Học Xã Hội, 821 p.

NGUYẼNN ĐÖNG CHI

1964 "Vai trò của đằng cấp và giai cấp trong các phong trào khởi nghĩa nông dân và chiến tranh nông dân ở nửa đầu thế ký XVI và giữa thế ký thứ XVIII" (Le rôle des castes et des classes sociales dans les jacqueries et les guerres paysannes de la première moitié du XVI $\mathrm{I}^{\mathbb{C}}$ siècle et de la seconde moitié du XVIII" siècle), Hanoi, Nghiên cưul lich sü n ${ }^{\circ}$ 60, p. 19-26.

NGUYẼN HÄI YÉN, PHAN NGOC LIÊN, NGUYẺN CÁNH MINH, NGUYẺN SĨ QUÉ

2002 Phong trào nông dân đàng ngoài thế ki XVIII : Bàn đò̀ (Les mouvement paysans au nord du Vietnam au XVII" siècle : les cartes), Hanoi, Trung tâm bản đồ và tranh ảnh giáo dục. Une carte en couleur de format $66 \times 100 \mathrm{~cm}$.

NGUYẺN KHÄC XU'ONG

1985 "Về vùng đất đai phủ An Tây, trấn Hưng-Hóa thời Lê mạt" (Sur les terres périphériques de la préfecture de An Tây, province de Hưng-Hóa, sous les derniers rois Lê), Hanoi, Nghiên cinu lich sii, 1985, n²20, p. 42-47.

NGUYẺN PHAN QUANG

2006 "Khời nghĩa Hoàng Công Chất 1739-1769", [la juste révolte de Hoàng Công Chất] Hanoi, Nghiên ciru lịch siti, 1985, n³ 358, p. 15-27.

NGUYẼ̃N VÄN HOÀN

1973 "Phong trào khởi nghĩa nông dân và văn học Việt Nam thế kỷ XVIII và nửa thế ky XIX" (Les mouvements insurrectionnels paysans et la littérature vietnamienne du XVIII" au XIX siècle), Hanoi, Tạp Chi Văn Họ $\mathrm{n}^{\circ} 4$ (1973): 26.

NGUYẺN VÄN HUYÊN

1938 "Contribution à l'étude d’un génie tutélaire annamite, Li Phúc Man », $B E F E O X X X V I I I 1938 / 1$, p. $1-110$.

1965 "Cuộc khơi nghĩa Lê Duy Mạt (1738-1770) có phài là cuộc khời nghĩa nông dân không ?" (l'insurrection de Lê Duy Mật est-elle une insurrection paysanne), Hanoi, NCLS, $1965, n^{\circ} 81$ p. 44-49.

NGUYẺN VĂN KHOAN

1951 «Essai sur le đình et le culte du génie tutélaire des villages du Tonkin » $B E F E O$ XLV (1951/1) p. 89-119.

NGUYĖN XUÂN LINH

1981 «Panorama des mouvements paysans vietnamiens (1918-1922)»p.83110 in: Histoire de l'Asie du Sud-Est, révoltes, réformes, révolutions. Pierre Brocheux éd., Presses Universitaires de Lille. 278 p. 


\section{PIIAN KIEN GIA.NG}

1998 "Mương thanh vung huyền thoại" (Mương Thanh terre de légendes). in

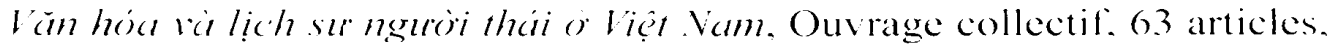
Hà Nội, 1998. Nhà xuất bạn văn hóa dân tộc, 696 p. p. 374-381 paru en français sous le titre "Mường Thanh terre de mythes" Études rietna-

PHAM ĐINH HO miennes, n² (136), 2000), numéro spécial Études Thaï (II), p. 129-136.

1789-1802 Vît lrung tị hit (Au fïl du pinceau par temps de pluie), entre 1789 et 1802. Présentation et annotations par Trưong Chinh, sur la base de la traduction du texte en caractères par Đông Châu Nguyễn Hữu Tiến (Nam Phong. 1927). Hà Nội. NXB Văn Học. 1972. 215 p. réédition à Paris. Sudestasic. 1985.

PHAM THẠN DUATT

1856 Hung Hóa Ki Lurọc (Histoire et géographie de la province de Hưng-Hóa). compilé en 1856, description du territoire et des coutumes, sites histori-

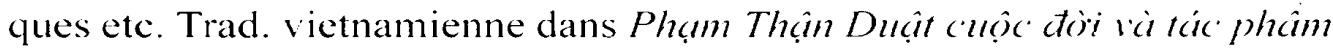
Hà Nội, 2000, NXB Văn hoá Thông tin. 838 p. réédition avec le texte en caractères.

\section{QUOC SÜ QUÁN}

1882 Dại nam nhât thống chi (Encyclopédie du Đại-Nam), Trad. Viet. Viện Su Học. Rééd NXB Thuận-Hóa 1997, 5 vol.

1884 Khâm định Việt sü thông giam cuơng muc (Version impériale du Texte et commentaire du Miroir général de l'histoire Việt). Trad. Viet. Viện Sur Học, Rééd. Hanoi, NXB Giáo Dục, 2 vol. 1203 p. et 1206 p.

1886 Đòng Khính dị du chi hrợ (Géographie descriptive de l'empereur Đồng-Khánh) (1886-1888). édition et traduction en vietnamien, chinois, anglais, français par Ngô Đức Thọ, Nguyễn Văn Nguyên. Ph. Papin. édition Hanoi, EFEO Hanoi - EPHE - Institut Hán-Nôm 2003. 3 vol. 2800 p., 300 cartes.

1884 Khâm dịh Việt sü thông giám curong muc (Version impériale du Texte et commentaire du Miroir général de l'histoire Việt) Traduction vietnamienne Viện Sư Học. Réédition Hanoi, NXB Giáo Dục, 1998 en 2 vol. 1203 et $1206 \mathrm{p}$.

TCNCLS (comité de rédaction de la revue Nghiên ciúu lịch sir)

1965 "Thảo luận về những cuộc khởi nghĩa cúa nông dân và chiến tranh nông dân trong quá trình lịch sư Việt Nam" (Discussion sur les insurrections et les guerres paysannes dans le processus historique vietnamien), Hanoi, Nghiên cumulich sir, 1965, n 76. p. 27.

Trécilorí, Benoît (de)

2001 Héros et Révolution au Viêt Nam, Paris, L'Harmattan, 444 p.

TRUOONG HŨ'U THIÊM

1998 "Ai về Bän Phu - Mường Thanh" (Complainte sur Ban Phu - Mường Thanh), Hanoi, Xura \& Na! $n^{\circ} 49$, p. 10-11.

VIEN THÔNG TIN KHOA HOC XÀ HÖI

1996 thu muc thần tich thàn sắc (Bibliographie des légendes des génies aux villages vietnamiens et des brevets royaux de divinisation), Hanoi. Viện Thông tin Khoa Học Xà Hội. 1276 p. 